\title{
The Passage of Vitamin A from Mother to Young in the Rat
}

\author{
By K. M. HENRY, S. K. KON, E. H. MAWSON, J. E. STANIER \\ AND S. Y. THOMPSON \\ National Institute for Research in Dairying, University of Reading
}

(Received 13 August 1949)

In studying the vitamin A content of human milk Kon \& Mawson (I950) noted that many of the women whose milk was examined had taken a supplement of vitamin A during pregnancy but not after the birth of the child. Although these women presumably had higher liver reserves of vitamin $A$ than those that had taken no supplement, the difference was not reflected in the vitamin A content of their milk.

Dann (1932, 1934a, b) and Baumann, Riising \& Steenbock (1934) studied the effect of the liver reserves of the mother rat on the stores of the newborn young and of the young at weaning. They did not analyse the milk; at that time methods of measuring vitamin A were not sufficiently sensitive for the purpose. Nevertheless, a comparison of Dann's values for the newborn with those for the weanling indicates that large differences in maternal reserves must have been reflected in small differences in the vitamin A content of the milk.

The work with rats now described was undertaken to study further the relationship between the maternal reserves of vitamin $A$, the vitamin $A$ content of the milk, and the stores of vitamin $A$ present in the young at birth and amassed during suckling. The mother rats received vitamin $A$ either preformed or as $\beta$-carotene.

\section{EXPERIMENTAL}

\section{General procedure}

Female hooded Norwegian rats from our colony were used throughout this work. Except in Exps. I and 6, the animals were weaned on to a diet low in vitamin A (diet 2r3) supplemented with sufficient vitamin A to maintain growth; the amount varied between 5 and 20 i.u. daily in different experiments. The percentage composition of diet 213 is given in Table 1 . Since the vitamin A and carotene content of this diet was equivalent to a vitamin A activity of not more than $8 \mathrm{i} . \mathrm{u} . / \mathrm{roo}$ g., it is unlikely that the vitamin $A$ intake from the diet amounted to more than $I$ i.u./rat/day. The vitamin A supplement was a concentrate prepared by Distillation Products Inc., kindly given to us by Dr T. H. Mead of British Drug Houses Ltd., and found by him to contain $170,000 \mathrm{i} . \mathrm{u} . / \mathrm{g}$. This was suitably diluted with arachis oil for feeding by pipette. During the preparatory period vitamin A was given weekly together with 35 i.u. of vitamin $\mathrm{D}$, also in arachis oil.

When the animals were $3 \frac{1}{2}$ months old and weighed about $200 \mathrm{~g}$., daily vaginal smears were taken and at oestrus they were mated with stock-colony males. Only eight young (four males and four females, if possible) were retained from litters con- 
taining more than this number. Between the $13^{\text {th }}$ and 2 rst days of lactation the mother rats were milked by machine as described by Houston \& Kon (1939). For this purpose the young were separated from the mother $17-20 \mathrm{hr}$. before milking. If insufficient milk was obtained at one milking, the sample was stored in the refrigerator and second, and sometimes third, samples were obtained at 2-day intervals and mixed with the first sample for analysis. The young were returned to the mother for a day between milkings. After the final milking, the mothers and their young were killed and the livers taken for analysis. Samples of blood were obtained from the mothers only.

\section{Table I. Percentage composition of the experimental diets}

Whole wheat Component

Linseed cake

Casein (crude)

Dried brewer's yeast

Calcium carbonate

Sodium chloride

Dried skim milk

Arachis oil (semi-hardened)

Red palm oil containing 850 i.u. carotene/g.*

Arachis oil containing $850 \mathrm{i}$.u. preformed

$\begin{array}{cc}\text { Diet 213 } & \text { Diet 275 } \\ 55 \cdot 2 & 49 \cdot 2 \\ 11 \cdot 2 & 11 \cdot 2 \\ 4.8 & 4.8 \\ 4.0 & 4 \cdot 0 \\ 0.4 & 0.4 \\ 0.4 & 0.4 \\ 20 \cdot 0 & 20 \cdot 0 \\ 4.0 & 10 \cdot 0 \\ - & - \\ - & -\end{array}$

Diet 276
$49 \cdot 2$
$11 \cdot 2$
$4 \cdot 8$
$4 \cdot 0$
$0 \cdot 4$
$0 \cdot 4$
$20 \cdot 0$
-
$10 \cdot 0$
-

Diet 277

vitamin $\mathrm{A} / \mathrm{g}$.

- On the basis $0.6 \mu \mathrm{g} . \beta$-carotene or $1 \cdot 2 \mu \mathrm{g} . \alpha$-carotene $\equiv \mathrm{I}$ i.u. See p. 313 .

In certain experiments it was desired to examine milk secreted in the early stages of lactation. This was done by removing the clotted milk from the stomachs of one or two young of a litter that had recently suckled. Since this involved a reduction of the litter, it was not done frequently, and the size of such litters was not restricted at birth. A comparison made in the later stages of lactation (see p. 311 ) showed that the vitamin A content of the clot, expressed as concentration in the fat, agreed reasonably well with that in the fat of the milk obtained directly from the mother. However, owing to admixture of digestive juices and changes in water content, the vitamin $\mathbf{A}$ content of the whole clot could not be compared with that of milk.

The vitamin A contents of the milk (diluted $\mathrm{x}$ : 10 with water) and of the blood plasma were determined by the methods used by Kon \& Mawson (I950) for human milk and plasma. Liver vitamin A was extracted by the method of Davies (1933). All measurements were made in the photoelectric spectrophotometer of Thompson (1942, 1949) calibrated as described by Kon \& Mawson (1950).

The difficulty of avoiding sampling errors in the determination of the fat content of human milk has been fully discussed by Kon $\&$ Mawson (1950). The great variability of the values now obtained for rat's milk (cf. Tables 2-8) suggests that similar diffculties are encountered with it. It is, therefore, uncertain (see p. $3^{16}$ ) whether the vitamin A content of rat's milk is better expressed as concentration in the milk or in the fat. We have given both values where possible, but neither method is completely satisfactory. 
Experiment 1. The effect of the level of vitamin $A$ intake during lactation of mother rats, previously maintained on a diet rich in vitamin $A$ and carotene, on the vitamin $A$ content of the mother's milk and blood plasma and of the livers of mother and young: preliminary experiment

This was a preliminary experiment in which stock-colony female rats were reared, and maintained until parturition, on our stock diet (Folley, Ikin, Kon \& Watson, 1938). This diet is very rich in vitamin A and carotene as it contains plentiful supplies of milk, liver and carrots. Eight rats were used. After parturition four of them continued on the stock diet while the other four were given the diet deficient in vitamin A used by us at that time for vitamin $A$ assays. This diet had the following percentage composition: ashless extracted casein (Glaxo Laboratories Ltd.) I5, gelatinized potato starch 63 , dried brewer's yeast 12 , salts 5 , arachis oil 5 . With the first group precautions were taken to prevent access by the young to the diet of the mother.

Table 2 gives figures for the vitamin A concentration in the milk, livers and blood plasma of the mothers, and in the livers of the young, towards the end of lactation. As would be expected, the maternal liver reserves were high and there was little difference between the two groups, evidently the period on the vitamin A-deficient diet was too short to exert any effect. The milk of the 'deficient' group was only slightly inferior in its vitamin A content to that of the group that received the stock diet. On the other hand, the vitamin A reserves in the livers of the young in the stockdiet group were some four times higher than those of the group on the deficient diet. This indicates that the ability of the young to store vitamin A depended on the vitamin intake of the mother during lactation rather than on her liver reserves. The poor correlation between the vitamin A content of the livers of the young and of the mother's milk will be discussed later.

Experiment 2. The influence of the vitamin $A$ content of the diet during lactation on the vitamin $A$ content of the mother's milk and blood plasma and of the livers of mother and young

Female rats were weaned on to diet 213 , and after 3 weeks on this diet were given as a weekly dose the equivalent of 5 i.u. vitamin A daily. This quantity was subsequently increased to $7.5 \mathrm{i}$.u. and, during the week before mating and during gestation, to ro i.u. At parturition the animals were divided into three groups to receive every day doses of 10,80 and I 60 i.u. vitamin A. The mothers were milked from the i6th day of lactation onwards.

The results are shown in Table 3. The vitamin A reserves of the livers of mothers and young increased with the size of the dose given to the mother. In group I, only traces of the vitamin were found in the livers of the mothers. In this experiment, therefore, we were fortunate in striking just the amount of vitamin A required for maintenance only. Subsequently we were unable to repeat this and could not avoid a small storage of vitamin $A$ in the livers of mothers and young. In group 2, the mothers stored less than $30 \%$ of the 3000 i.u. vitamin A taken during lactation. Group 3, which received twice as much, stored rather more than $30 \%$, and more 


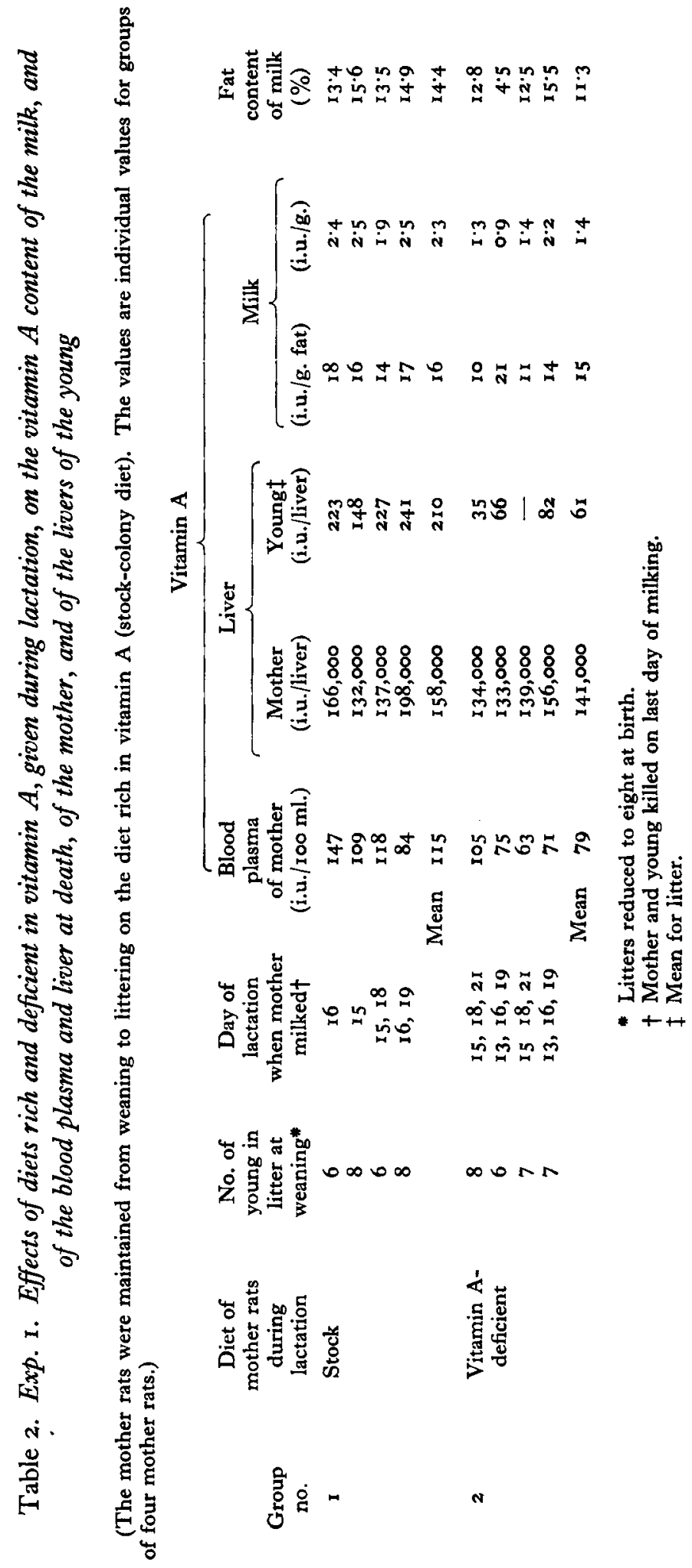


Vol. 3

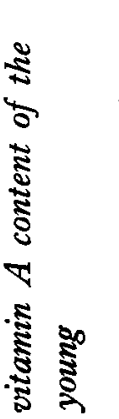

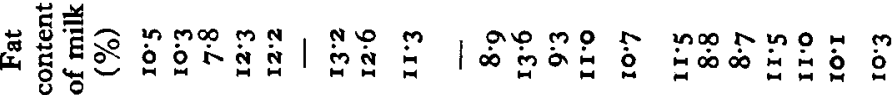

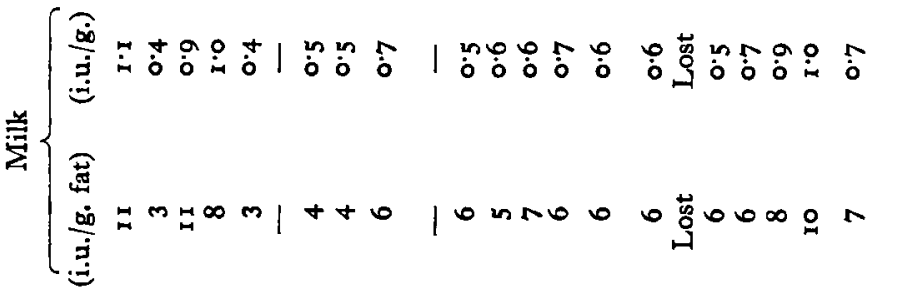

$\frac{1}{4}$

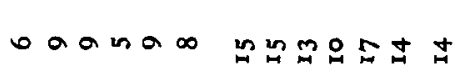


than twice as much vitamin $A$ was found in their livers as in those of group 2. The mean vitamin A content of the blood plasma of the mothers in group I was lower than that in groups 2 and 3 . The young in group I stored negligible amounts of vitamin $A$; those in groups 2 and 3 stored on the average about 8 and $\mathrm{I}_{4}$ i.u., respectively. Yet young in all three groups grew at the rate of about $\mathbf{I}$ g. daily and presumably took similar amounts of milk, and the milk, when analysed towards the end of lactation, had a similar vitamin A content in all groups. It seemed likely, therefore, that the differences in liver reserves of the young were due to differences in intake of vitamin $\mathrm{A}$ before the 16 th day of lactation. Experiments to test this point are described below.

Experiment 3. The influence of large differences in the maternal intake of vitamin $A$ on the vitamin $A$ content of the mother's milk and blood plasma at intervals during lactation and of the liver of mother and young

The results of Exp. 2 showed that the vitamin A intake of the mother was not reflected in the vitamin A content of her milk at the end of lactation, though it seemed likely that it affected the composition of the earlier milk. Difficulties in milking the rats at the beginning of lactation made it necessary to use another method to obtain milk at this stage. This was done as described on p. 302.

Female rats were weaned on to diet 213 and received doses of 7.5-10 i.u. vitamin A till a week before the taking of vaginal smears was started (see p. 301 ), when the dose was increased to $20 \mathrm{i}$.u. daily. When the litters were born, the mothers were divided into four groups of eight, of which three received single doses of 640,3170 and I 5,800 i.u. vitamin $A$ and one, group I, was given a daily dose of 20 i.u. In group I, five of the eight mothers and their litters were killed on the Ist day of lactation, of the other three mothers two were killed on the 17 th, and one on the 22nd, day of lactation; their respective litters were killed on the previous day. Before dosing, in each of the groups 2, 3 and 4, pups were killed, and their livers and the milk clots from their stomachs were analysed for vitamin A; further pups were killed on the 2nd, $3^{\mathrm{rd}}$, $15^{\text {th }}$ and $I 6$ th days of lactation; on the $I 7$ th day the mothers were milked and then killed and their blood and livers analysed. In order to obtain more adequate samples, litters horn on the same day were pooled for analysis, one or more pups from each litter being used on each day. When the mothers were killed, their blood and livers also were pooled. With the samples bracketed in Table 4 , the milk obtained by milking was kept in cold storage until that for the group had been pooled.

The results are given in Table 4. They show that within $24 \mathrm{hr}$. of dosing there was an increase, varying with the vitamin $A$ intake, in the vitamin $A$ content of the milk but that by the $15^{\text {th }}$ or 16 th day of lactation the same steady level was reached in all groups. The liver reserves of the young in groups 2,3 and 4 increased within $24 \mathrm{hr}$. after dosing of the mother and continued to rise throughout lactation, the response being related to the size of the dose. In this experiment all mother rats received $20 \mathrm{i} . \mathrm{u}$. vitamin A daily during pregnancy, double the dose given to all mothers in Exp. 2. Dosing at this rate was continued during lactation in group $\mathbf{I}$ in both experiments. It is not surprising, therefore, that the young in Exp. 3 were born with small reserves 


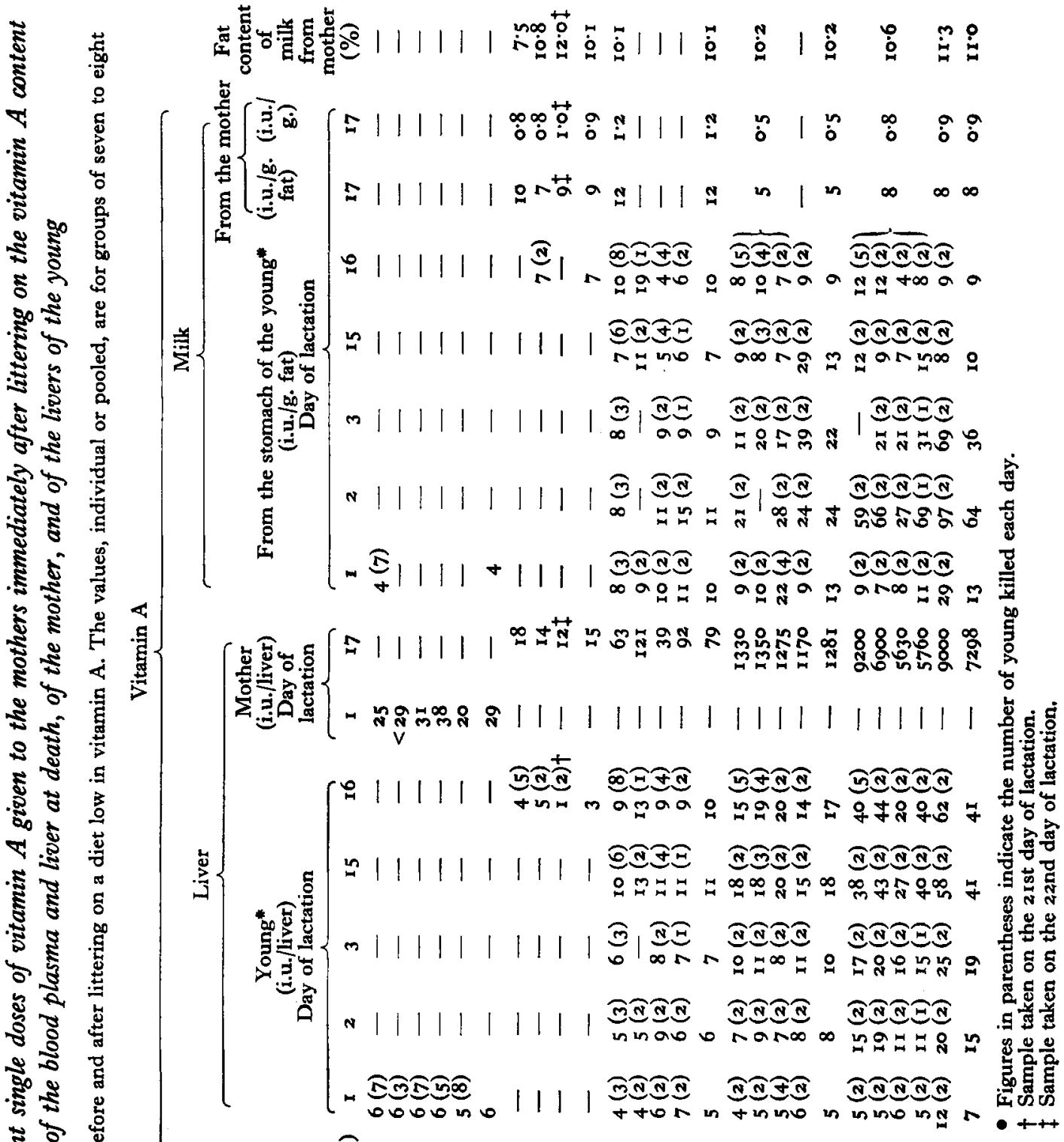

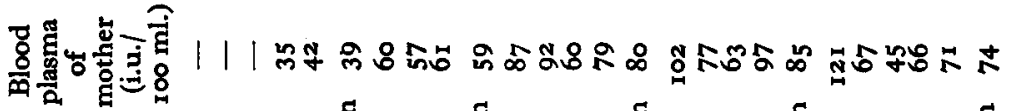

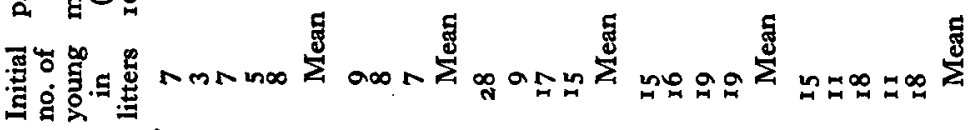

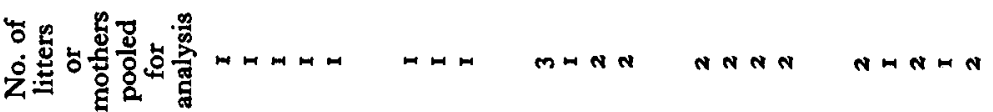

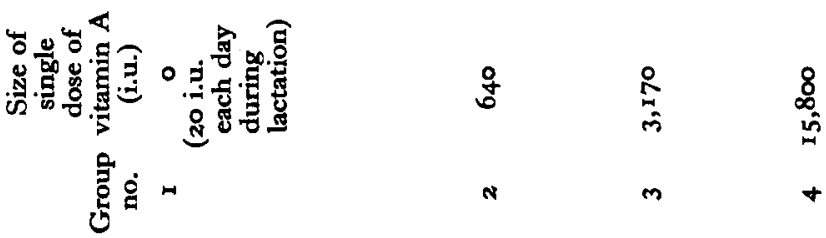


of vitamin A. The livers of the mothers, at the end of lactation, contained measurable amounts of the vitamin in contrast to those in group I of Exp. 2. Does in group 3 of the present experiment received five times as much vitamin $A$ as those in group 2 , and stored correspondingly more. The final reserves of the young in group 3 were nearly twice as large as of those in group 2.

Experiment 4. The relation of the maternal liver reserves to the vitamin $A$ content of the milk and blood plasma and of the livers of the suckling young: preliminary experiment

In this preliminary experiment does were used which in earlier experiments had received small doses of vitamin $\mathrm{A}$ and had failed to become pregnant or had lost their litters. Groups of five were given 2000, I1,000 or 54,000 i.u. vitamin A in four doses over a period of 10 days before mating or remating. At parturition, the blood plasma of two mothers in each group, and the livers of these mothers and of their young, were analysed for vitamin $A$. The remaining animals were milked on the I8th-2Ist days of lactation and then killed, and the blood, milk and livers of the mothers and the livers of the young were analysed for vitamin $\mathrm{A}$.

The results are shown in Table 5. Once again no differences were found at the end of lactation in the vitamin A concentration of the milk of the different groups. At birth, the concentration of vitamin $A$ in the livers of the young was similar in all groups; no increase was found in group $I$ at the end of lactation, but the reserves increased in group 2 and, more markedly, in group 3 . The differences were not directly proportional to the size of the maternal store. Thus a fiftyfold difference in maternal liver reserves between groups $I$ and 3 resulted in a threefold difference in the reserves of the young.

Experiment 5. The relation of the maternal reserves of vitamin $A$ to the vitamin $A$ content of the blood plasma and of the milk at intervals during lactation, and to the liver reserves of the suckling young

As in the previous experiments female rats were reared on diet 213 with small daily supplements of vitamin $A$. One week before mating they were divided into three groups and given, in the course of 4 days, doses of 1850,9400 and 47,000 i.u. vitamin A. Immediately after parturition some mothers and litters were killed in each group and their blood and livers analysed for vitamin A. As in Exp. 3, young from the remaining litters were killed on the Ist, 2nd, $15^{\text {th }}$ and 16 th days of lactation and their livers and the milk clots from their stomachs were analysed; on the 17 th day the mothers were milked and killed, and the usual analyses were made.

The results are shown in Table 6. The marked differences in liver reserves of vitamin $A$ of the mother rats in this experiment were little, if at all, reflected in the reserves of the young at birth; the pups in group 3 may have been born with a few more i.u. of vitamin $A$ than those in the other groups. The differences towards the end of lactation were more pronounced though still slight. The quantity of vitamin A which the young were able to store during suckling bore almost the same relation to the maternal reserves of vitamin A as in Exp. 4 (cf. Table 5). Again, despite differences in the quantity stored by the young, there was no appreciable difference in the vitamin 
Vol. 3

Vitamin $A$ in rat lactation

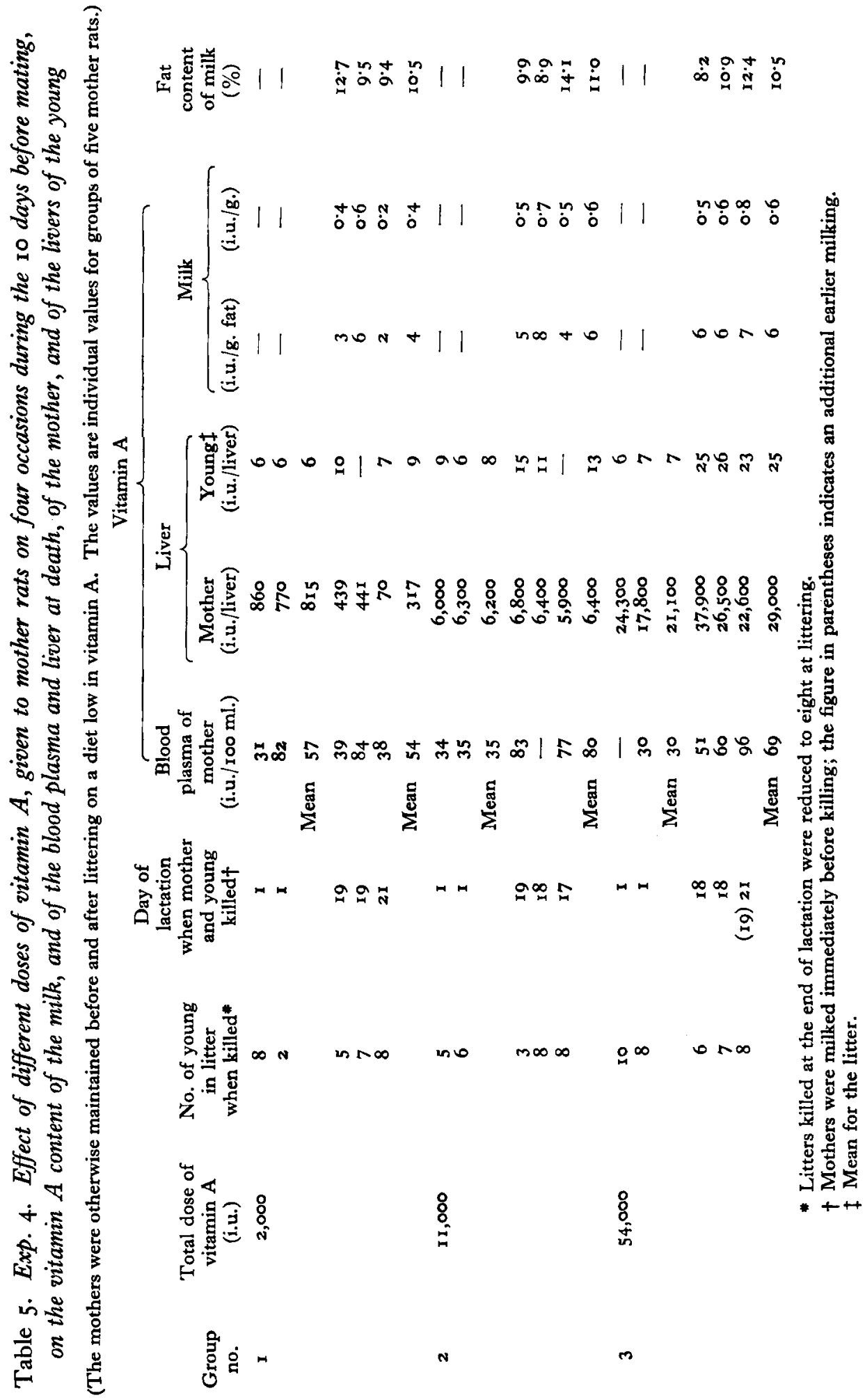




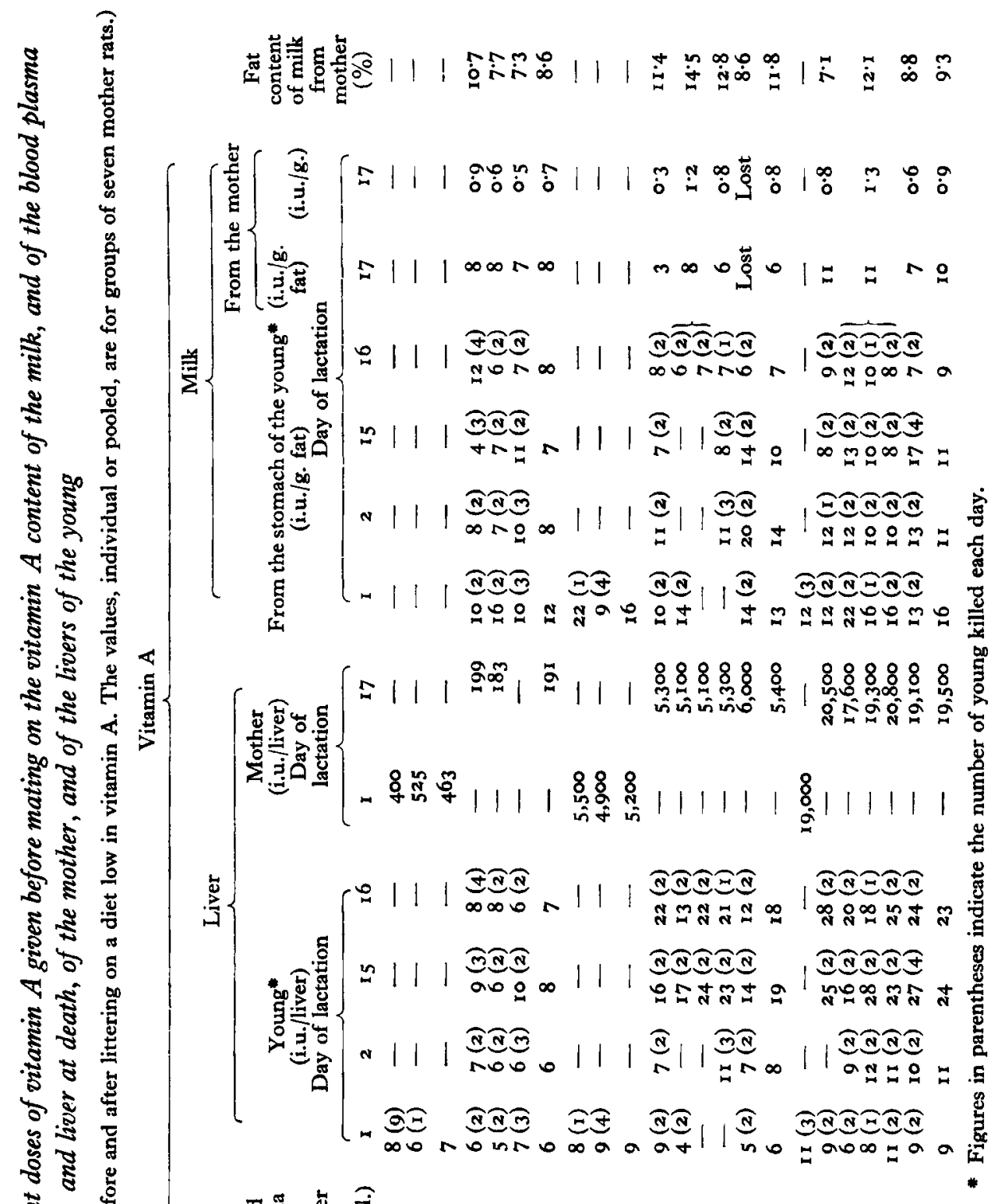

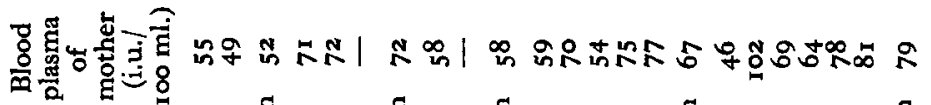

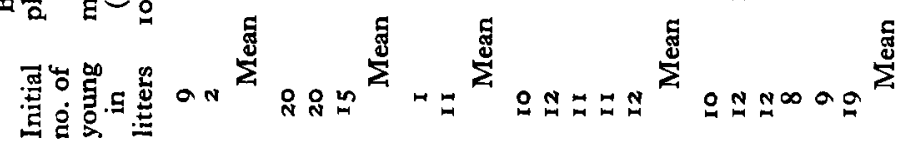

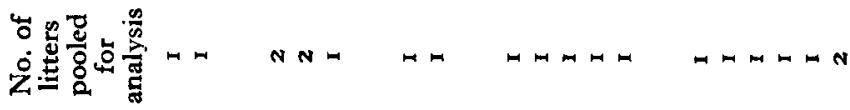

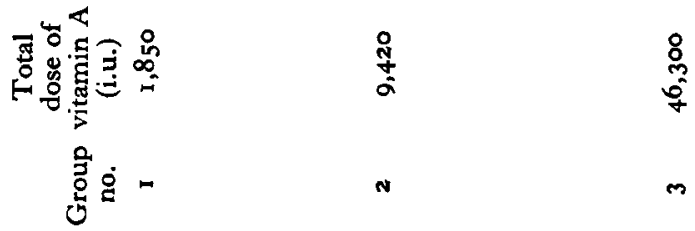


A content of the milk obtained at the end of lactation from rats with widely differing reserves of vitamin $\mathbf{A}$.

In this experiment the pups of mothers that had received about 45,000 i.u. before mating accumulated less vitamin A than pups of mothers given one-third of this quantity during lactation in group 4 of Exp. 3 (Table 4).

Values for the vitamin A content of milk fat determined on milk obtained by milking and from the stomachs of the young are given side by side in Tables 4 and 6 . On the whole, the agreement was reasonably good, though on a few occasions there were marked discrepancies.

Experiment 6. Changes in the course of lactation in the vitamin $A$ content of the milk of rats maintained on the stock-colony diet and of the livers of their young killed at intervals

It is not possible to tell from the experiments described so far whether in the rat, as in other species, the milk is richer in vitamin $A$ at the beginning of lactation than later on. In all these experiments the rats obtained the vitamin A not as they would normally, in the food, but as separate doses.

The lactational trend of vitamin A was, therefore, studied in the milk fat of stockcolony females. For this purpose females with large litters of eleven to thirteen pups were used. The stock diet (Folley et al. 1938) contains milk, carrots and liver as the chief sources of vitamin A and carotene. During lactation stock-colony mothers normally receive liver three times a week. In this experiment the liver was omitted as the occasional administration of such a rich source of vitamin $\mathbf{A}$ might distort the values obtained for the milk fat.

Milk was obtained for analysis from the stomachs of the young on the ist, 2nd, 5th, I2th and I6th days of lactation; the vitamin A content of their livers also was determined. On the $17^{\text {th }}$ day of lactation the mothers were milked by machine and the milk was analysed. The results are shown in Table 7 . It will be seen that the vitamin A content of the milk dropped rapidly during the first few days from about 12 to about 6 i.u./g. fat, that it then remained stationary, and that a possible further slight decrease occurred between the rath and 16 th days.

Two complicating factors make it difficult to say whether this picture really represents the lactational trend of vitamin $A$ in normal suckling. In the first instance, it is conceivable that the decline in concentration of vitamin $A$ with the progress of lactation was not physiological but connected with the change in the amount of vitamin $A$ in the diet caused by the omission of liver from it after the birth of the litter. Secondly, the size of the litter was constantly diminishing as pups were being killed for analysis, and thus the milk yield must have declined more markedly and rapidly than under normal conditions. The effect of this on the vitamin A content of the milk is a matter of conjecture, though a low yield of milk might be expected to be associated with an increase in concentration of vitamin $A$. 


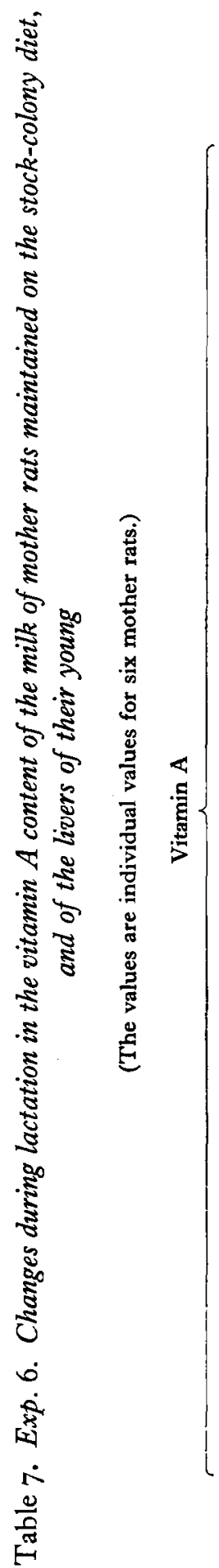

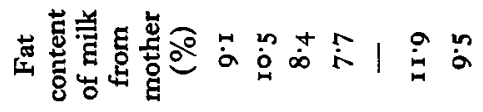

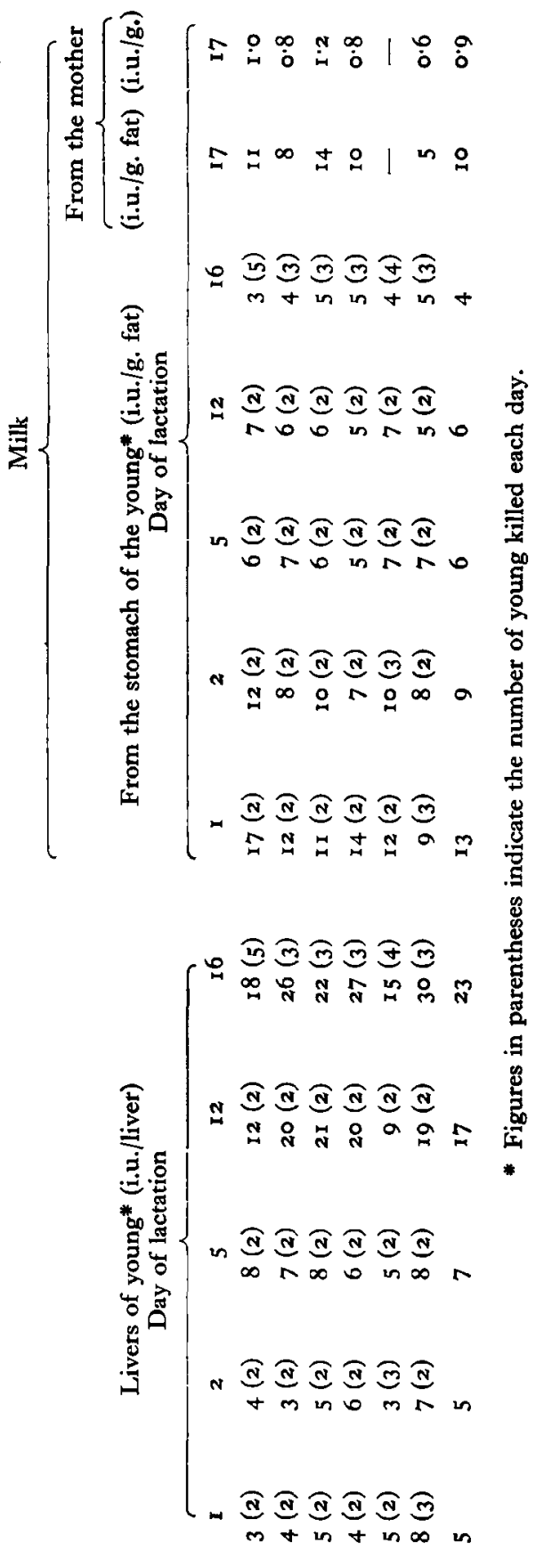

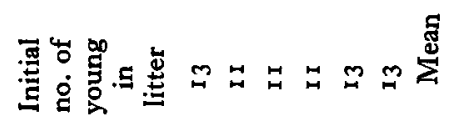




\section{Experiment 7. The relative efficiency in the utilization of vitamin $A$ and carotene by the rat during pregnancy and lactation}

Female rats were maintained from weaning on diet 213 supplemented with carotene, in the form of red palm oil, to supply the equivalent of $7 \cdot 5-10$ i.u. vitamin A daily. The red palm oil contained $4 \mathrm{ro} \mu \mathrm{g}$. $\beta$-carotene and $205 \mu \mathrm{g}$. $\alpha$-carotene $/ \mathrm{g}$, and the potency was calculated on the assumption that $0.6 \mu \mathrm{g}$. $\beta$-carotene or $\mathrm{I} \cdot 2 \mu \mathrm{g} . \alpha-$ carotene $\equiv I$ i.u. vitamin A. Immediately after mating the animals were divided into three groups and given diets 275,276 and 277 (see Table I). Diet 275 was supplemented with red palm oil to supply the equivalent of 20 i.u. vitamin A daily. On the 2Ist day of gestation, i.e. the day before parturition was expected, about half of the animals in each group were killed and the young removed from the uterus. The vitamin $\mathrm{A}$ was measured in the pooled blood plasma and individual livers of the mothers, and in pooled livers of each litter. The remaining does were allowed to carry to term and litter normally. Young were taken for analysis on the Ist, 4th and rath days of lactation, about one-third of the litter being killed on each occasion. Vitamin A was determined in the pooled livers and in the milk clots from the stomachs. The mothers were killed on the 12 th day of lactation, and their livers and a pooled sample of plasma from each group were analysed for vitamin $A$.

The results are given in Table 8. All measurements made on groups 2 and 3 , which received large quantities of vitamin $A$ or carotene, show clearly that preformed vitamin A was more efficiently utilized. Thus the liver reserves of vitamin A of the mothers on the 21st day of gestation were some three times higher in group 3 than in group 2, and the corresponding differences for the livers of the young, although small, were statistically significant. This difference in favour of group 3 rapidly became more marked as lactation proceeded; for the mothers the liver reserves increased by some $50 \%$ in group 2 and by some $75 \%$ in group 3 between the 2 rst day of gestation and the I2th day of lactation. For the young animals the corresponding increases were 600 and $1400 \%$, respectively. Initially the vitamin A content of the milk fat of group 3 was double that of group 2, in which it decreased significantly during the first 12 days of lactation, whereas in group 3 there was no significant change. The values obtained in group 3 for the vitamin A content of the milk fat and of the livers of the young are higher than any found in earlier experiments, but it must be remembered that now the intake of preformed vitamin A was considerably higher. The vitamin was given mixed with the food and the food intake was not recorded, but experience in this Institute shows that mothers eat $20-25 \mathrm{~g}$./day of similar diets during pregnancy and up to $40 \mathrm{~g}$./day during lactation. On the assumption that the mean intake was $30 \mathrm{~g}$./day, the vitamin $A$ or carotene taken by each doe would amount to 84,000 i.u. for the whole experiment.

The results for group I show that, with a daily intake of 20 i.u. carotene, the livers of the young contained small but measurable amounts of vitamin A. The stores were slightly higher on the Ist day of lactation than on the 2ist day of gestation, owing to the intake of vitamin A from the colostrum, but did not increase further. The liver reserves of the mothers were low, but higher on the I2th day of lactation than at the 


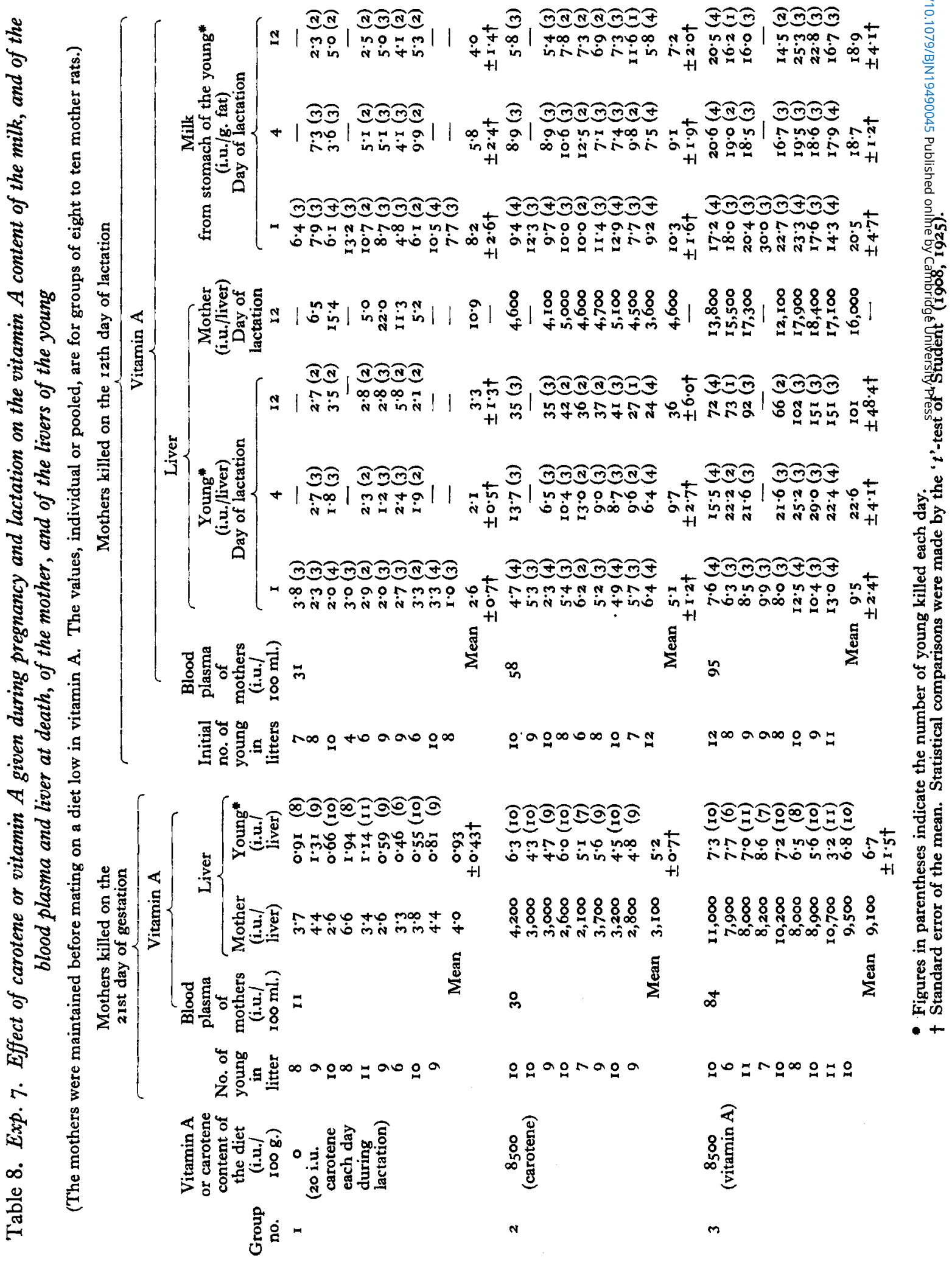


end of gestation. The level of vitamin $A$ in the milk fat was just significantly lower than that for group 2 and dropped significantly $(50 \%$ ) by the 12 th day. Group I in Exp. 2 received comparably low quantities of vitamin $A$, ro i.u. daily. The vitamin A content of the milk fat was similar in the two experiments. In the present one the sample was obtained from the milk clot in the stomachs of the young on the 12th day of lactation, whereas in the earlier test the sample was obtained by milking the mothers on the I6th-22nd days of lactation. The liver reserves of both mother and young were somewhat higher in this test. The results suggest that a daily intake of 20 i.u. carotene was at least as well utilized as one of Io i.u. preformed vitamin A. Group I, in Exp. 3, also received quantities of preformed vitamin $A$ similar to those of carotene given to group $\mathrm{I}$ in this experiment. Again a comparison of maternal and foetal liver reserves indicates that with these low levels carotene was as efficiently utilized as vitamin A.

The changes in the blood vitamin $A$ are most interesting. In all groups there was a definite rise between the end of gestation and the 12 th day of lactation, more marked in the two groups receiving carotene than in the group receiving preformed vitamin $\mathrm{A}$ (cf. Table 8). It is unfortunate that no measurements were done during gestation. The figures indicate that, as in other mammals (Braun, 1945; Sutton, Kaeser \& Soldner, 1945; Hoch \& Hoch, 1946), the vitamin A content of rat's blood decreases during gestation. The change was more marked when the intake of the vitamin, and consequently the liver reserves, were low. It is possible that the liver stores of vitamin A alcohol which, according to Glover, Goodwin \& Morton (1947), are strongly correlated with the blood level, may have a buffering effect, but were too low in group I to exert it efficiently.

\section{DISCUSSION}

Although the main object of this investigation was to determine the relationship between the vitamin A content of the milk and that of the diet of the mother and her liver reserves, the values obtained for milk are themselves of interest. As far as we are aware no new data have been published for the vitamin A content of rat's milk since the report of Houston \& Kon (1939). For a mixed sample of milk obtained at the end of lactation, containing I I $7 \mathrm{~g}$. fat $/ 100 \mathrm{ml}$., they found a value of $36 \mathrm{Moore}$ blue units $/ \mathrm{g}$. fat.

Measurements carried out since then in which values obtained with a Lovibond tintometer were compared with those obtained with the photoelectric spectrophotometer of Thompson (1942, r949) show that, under our conditions, I Moore blue unit is equivalent to 0.38 i.u.* Recalculation on this basis and on the assumption that the specific gravity of rat's milk is $\mathrm{I} \cdot 05$ (Cox \& Mueller, I937) gives a value of $\mathrm{I}_{5} \cdot \mathbf{\text { i.u. }} / \mathrm{g}$. milk or $13 \cdot 7$ i.u./g. fat.

Our values for individuals at the end of lactation ranged from 0.4 i.u./g. milk or 3 i.u./g. fat, for rats with negligible liver reserves of vitamin A and receiving very little of it in their diet (Table 3), to 2.5 i.u./g. milk or 18 i.u./g. fat for stock-colony rats that received liver before and during lactation (Table 2). On account of the varying

- This shows that the provisional factor for the conversion of Moore blue units to mg. vitamin A put forward by Bartlett, Cotton, Henry \& Kon (r938) was about twice too high. 
conditions in the present experiments no mean value can be given, but the figure of Houston \& Kon (1939) lies well within the present range.

As already pointed out on p. $3^{\circ 2}$, the vexed question of the influence of sampling errors on the fat content of milk is a very real problem in dealing with human milk or with the milk of small animals which it is impossible to milk completely. Any error in assessing the fat content naturally leads to a similar error in measurement of fatsoluble vitamins. The difficulty can partly be overcome by expressing the results in terms of concentration of the vitamin in fat but the interpretation of such results is difficult since nothing is known about individual variations in fat content. An example of this is shown in Table 2. The results for the vitamin A content of milk fat in group I were fairly uniform, but in group 2 the value for the second rat was much higher than those for the others. The fat content was, however, only $4.5 \%$, very much lower than the general mean, and as a result the vitamin A content of the milk was lower than that of the rest of the group. The interpretation of such results depends on the fat content of the sample being fully representative, and this cannot be decided without analysis of a series of samples from each animal. This, because of difficulties of milking at the beginning of lactation, could not be achieved in the present study.

Our preliminary experiment (Exp. I) suggested that the vitamin A content of the mother's diet might be more important than that of her reserves in determining the amount of vitamin A received by the young during suckling. The results set out in Tables 3 and 4 show that, in fact, the amount of vitamin A stored by the young varied with the amount consumed by the mother during lactation. The difference in the vitamin A content of the milk fat of rats receiving different amounts of vitamin $A$ was most marked in the early part of lactation and scarcely appreciable at the end ('Table 4). The peak was on the 2nd and not on the ist day, probably because a dose of vitamin A was given to the mothers after the first samples of milk had been taken. The failure of dietary vitamin A to influence the vitamin A content of milk fat at the end of lactation may have been due to an increased rate of uptake by the liver or to a change in the functional activity of the mammary gland. These results for milk are confirmed by those shown in Table 4 for the vitamin A content of the livers of the young. Thus the rate of storage of vitamin A was greatest with the highest vitamin A content of the milk fat.

Tables 5 and 6 show that, in the absence of vitamin A from the diet, the amount stored by the young during suckling varied with the extent of the maternal reserves. This confirms the findings of Dann (1932, 1934a, b). However, the differences were relatively very small. The results obtained for the vitamin A content of milk are not very clear-cut, and the small differences found seem hardly sufficient to account for the differences observed in the liver reserves of the young, even when the cumulative effect of storage is taken into account.

The relative influences of vitamin $\mathbf{A}$ in the mother's reserves and in her diet were studied in Exps. 3 and 5, carried out simultaneously. In Exp. 3, vitamin A given during lactation had a marked effect on the vitamin A content of the milk: $c .16,000$ i.u. vitamin A thus given resulted in the storage of 5000-9000 i.u. by the mother and of c. 34 i.u. by each of the young (Table 4). In Exp. 5, of 46,000 i.u. (nearly three times 
as much as in Exp. 3) given before mating, nearly 20,000 i.u. were stored by the mother and only about 13 i.u. by each of the young (Table 6).

It is known from experiments with other animals and from observations with man that the vitamin A content of milk is much more easily affected by dosing during lactation than by stores already present in the liver, probably because these are held tenaciously, whereas vitamin $A$ appearing in the circulation after the administration of substantial quantities is more available for passage into milk. In fact, with large doses the rapid uptake from the gut may lead to temporary swamping of physiological barriers and to spill-over of the vitamin into the milk. Thus it is possible that vitamin $\mathrm{A}$ given in a more uniform way in the food might, even during lactation, have less effect than when given in discrete doses, though the effects of these might only be quite transient. Nevertheless, a comparison of the results of Exp. 7 (Table 8) and Exps. 4 and 5 (Tables 5 and 6) shows that does receiving vitamin $A$ in the diet during lactation passed on more of it to their young than does with liver reserves higher, but laid down before they started nursing.

If dietary vitamin $A$ is more easily available for secretion into milk, the diet of the mother during lactation should be well supplied with it especially if it is desired that young animals should begin independent life with a plentiful reserve. Large doses given during gestation would be less effective.

If it is permissible to reason from rat to man these results afford an explanation of our finding (Kon \& Mawson, r950) that the milk fat of women that had received extra vitamin A during pregnancy was not particularly rich in this factor. It is clear that, in the rat, extremely large differences in vitamin A reserves are required to produce even small differences in the vitamin A content of milk fat at the beginning of lactation, and in later lactation there is unlikely to be any difference at all. Adequate supplies of vitamin $\mathbf{A}$ given during lactation are likely to obscure any differences resulting from differences in liver reserves.

On several occasions in this study the vitamin A in the blood of mother rats was measured just before or immediately after the birth of the litter and also in later lactation. The values in later lactation were consistently higher (Tables $4^{-6}$ ), even when lactation was depleting the liver reserves (Table 4, group I; Table 6, group I). The rat therefore behaves, in this respect, like man (Hoch \& Hoch, 1946) and the bovine (Braun, 1945; Sutton et al. 1945).

From some of the results obtained in Exps. 3-5 it is possible to form an estimate of the quantity of vitamin A used by mother rats for purposes of lactation. Thus in Exp. 3 (Table 4), comparison of the values for the liver reserves of the five mothers in the control group, group I, killed at the beginning of lactation with those for the three killed towards the end indicates that, whereas they managed before littering to retain some vitamin A from a daily allowance of 20 i.u., they were drawing on their reserves while suckling their young. The mothers in group 2, which received a single dose of 640 i.u., corresponding to about $40 \mathrm{i}$.u. daily as against the $20 \mathrm{i}$.u. daily of group I, increased their reserves by some 50 i.u. (79 i.u. less 29 i.u.). The additional 320 i.u. (640 i.u. less 20 i.u. daily for 16 days) endowed them with liver reserves some 60 i.u. (79 i.u. less 15 i.u.) higher than those of the controls, group r. The balance of 260 i.u. 
( 320 i.u. less 60 i.u.), or $\mathrm{I} 5$ i.u. daily, may be taken roughly as having been used by the mother for the needs of lactation.

In Exp. 4 (Table 5) an initial store of some 800 i.u. in the livers of mothers in group I was reduced by at least 300-400 i.u. by the 17 th-21st day. No assessment of this kind is possible for groups 2 and 3 , as the amount of vitamin $A$ used during lactation was too small in proportion to the total liver reserves. A similar calculation, which may be more accurate, for group I in Exp. 5 (Table 6) shows that some 250 i.u. of the maternal liver reserves were used for the maintenance of mother and young during the first I7 days of lactation. This works out at about 15 i.u. daily. In Exp. 3 (Table 4) a daily intake of about 35 i.u. $\left(\frac{640-(79-29) \text { i.u. }}{17}\right)$ was necessary to maintain the liver reserves of a lactating mother. Hence the efficiency of utilization was roughly of the order of $\frac{15 \text { i.u. }}{35 \text { i.u. }} \equiv c .45 \%$.

In these experiments the size of the litter changed with the progress of lactation as young were being killed for analysis, and it would be unreasonable to try to estimate the milk yield of the mother rats. If, however, the figures of Brody \& Nisbet (1938) are taken as an indication, their daily production was of the order of $25 \mathrm{~g}$. Tables $4^{-6}$ indicate that the vitamin A content of the milk was about $0.5-1 \cdot 0$ i.u./g. It would appear, therefore, that the 15 i.u. used daily by the mothers for purposes of lactation were quantitatively transferred to the milk.

\section{SUMMARY}

I. Female rats were reared on the stock-colony diet, or on a diet low in vitamin A supplemented with enough of the vitamin for satisfactory growth but not for storage. When mature the animals were mated with stock-colony males.

2. Vitamin A, preformed or as carotene, was given in single doses or daily, before or after the birth of the litters. Vitamin A reserves of mothers and young were measured at different stages. Blood from mothers, when killed, and milk obtained from the mother or from the stomachs of the young, were analysed for vitamin A.

3. At birth, young of mothers depleted of liver reserves contained only about I i.u. of vitamin A each in their livers. When the mothers' reserves varied from 30 to 20,000 i.u., the livers of the young contained from 5 to ro i.u., irrespective of the reserves of the mother.

4. The vitamin A content of the milk and of the livers of the young was influenced by the amount of vitamin A taken by the mother during lactation more than by her liver reserves.

5. When the mother depended only on her reserves, her milk at the end of lactation contained some $0^{\circ} 5^{-1} \cdot 0$ i.u./g., the content having been about twice that amount at the beginning. When vitamin $A$ was given during lactation, the value at the end, with the one exception in Exp. 1, was also $0.5^{-1} \cdot 0$ i.u./g., but the values in early lactation were much higher.

6. Liver reserves of the young increased some threefold when mothers with reserves of 20,000-30,000 i.u. received no vitamin A during lactation. A sixfold 
increase occurred when mothers with low initial reserves received a single dose of some 16,000 i.u. at the beginning of lactation.

7. When mother rats with initially low reserves of vitamin A were given vitamin A or carotene during gestation and lactation at the rate of 8500 i.u./100 g. diet, the vitamin $A$ was more efficiently used than the carotene. At the end of gestation the mean liver reserves were 9000 i.u. in the vitamin A group and 3000 i.u. in the carotene group; on the I2th day of lactation the corresponding figures were 16,000 and 4600 i.u. During the first 12 days of lactation the concentration of vitamin $A$ in the milk fat of the carotene group dropped significantly from to to 7 i.u./g.; it remained unchanged at about $20 \mathrm{i.u}$./g. in the vitamin A group.

8. The vitamin A concentration in the blood plasma of mother rats was lower immediately before and after parturition than in later lactation even when lactation was depleting the liver reserves.

9. It is estimated that a mother rat requires specifically for lactation about 15 i.u. of preformed vitamin A daily, and that that amount is probably quantitatively transferred to the milk.

\section{REFERENCES}

Bartlett, S., Cotton, A. G., Henry, K. M. \& Kon, S. K. (1938). F. Dairy Res. 9, 273.

Baumann, C. A., Riising, B. M. \& Steenbock, H. (1934). F. biol. Chem. 107, 705.

Braun, W. (1945). 7. Nutrit. 29, 6r.

Brody, S. \& Nisbet, R. (1938). Res. Bull. Mo. agric. Exp. Sta. no. 285.

Cox, W. M. Jr. \& Mueller, A. J. (1937). F. Nutrit. 13, 249.

Dann, W. J. (1932). Biochem. f. 26, 1072.

Dann, W. J. (1934a). Biochem. F. 28, 634.

Dann, W. J. (1934b). Biochem. F. 28, 2141.

Davies, A. W. (1933). Biochem. F. 27, 1770.

Folley, S. J., Ikin, E. W., Kon, S. K. \& Watson, H. M. S. (1938). Biochem. F. 32, 1988.

Glover, J., Goodwin, T. W. \& Morton, R. A. (1947). Biochem. F. 41, 97.

Hoch, H. \& Hoch, R. (1946). Brit. Y. exp. Path. 27, 3 I6.

Houston, J. \& Kon, S. K. (1939). Biochem. F. 33, 1655.

Kon, S. K. \& Mawson, E. H. (1950). Spec. Rep. Ser. med. Res. Coun., Lond., no. 269. (In the Press.)

'Student' (1908). Biometrika, 6, I.

'Student' (r925). Metron, 5, 105.

Sutton, T. S., Kaeser, H. E. \& Soldner, P. A. (1945). F. Dairy Sci. 28, 933.

Thompson, S. Y. (1942). Chem. \& Ind. 6r, 170.

Thompson, S. Y. (1949). Brit. F. Nutrit. 3, 43. 